\title{
Küresel Grafitli Dökme Demirin Nodülarite ve Küreselliğinin Görüntü İşleme Yöntemleri Kullanılarak Belirlenmesi
}

\author{
Ayşe Elif Canbilen ${ }^{1}$, Battal Bura Ürküt ${ }^{2 *}$ \\ ${ }^{1}$ Konya Teknik Üniversitesi, Mühendislik ve Doğa Bilimleri Fakültesi, Elektrik-Elektronik Mühendisliği Bölümü, Konya, Türkiye (ORCID: 0000-0003-1891-5703) \\ ${ }^{2}$ Konya Teknik Üniversitesi, Mühendislik ve Doğa Bilimleri Fakültesi, Elektrik-Elektronik Mühendisliği Bölümü, Konya, Türkiye (ORCID: 0000-0003-2277-9169)
}

( $1^{\text {st }}$ International Conference on Computer, Electrical and Electronic Sciences ICCEES 2020 - 8-10 Ekim 2020)

(DOI: $10.31590 /$ ejosat.802698)

ATIF/REFERENCE: Canbilen, A.E. \& Ürküt, B.B. (2020). Küresel Grafitli Dökme Demirin Nodülarite ve Küreselliğinin Görüntü İşleme Yöntemleri Kullanılarak Belirlenmesi. Avrupa Bilim ve Teknoloji Dergisi, (Özel Sayı), 60-64.

$\ddot{O} \mathbf{z}$

Dökümhaneler, endüstrideki önemli parçaların üretimini sağlamaları sebebiyle toplumun en önemli faaliyet eksenlerinden biridir. Dökümhanelerde, farklı elementlerin eritilmesi ve belli oranlarda birleştirilmesiyle elde edilen eriyik malzemeler, çeşitli işlemlere tabi tutulmakta ve kalıplanarak istenen şekle getirilmektedir. Üretilen dökümler, otomotiv ve silah sektörü, havacılık ve denizcilik endüstrisi gibi birçok farklı alanda kullanılmaktadır. Bununla birlikte, kullanıcıların ihtiyacına göre farklı özelliklerde üretilen dökme demirlerin kalite ve standardizasyon işlemlerinin sanayide mühendisler tarafından manuel olarak gerçekleştirilmesi ciddi iş gücü, zaman ve maliyet kayıplarına sebep olmaktadır.

Günümüzde hızla ilerleyen teknoloji, kullanıcıların ihtiyaçlarını her geçen gün daha da çeşitlendirmektedir. Bu noktada kalite süreçlerinin hızlandırılması, devamındaki bütün süreçleri hızlandırmakla kalmayacak; iş gücü, zaman ve maliyet kaybını da minimum seviyeye indirecektir. Bu durum göz önünde bulundurularak, bu çalışmada; küresel grafitli dökme demirin nodülarite ve küresellik değerleri baz alınarak bilgisayar destekli bir sistem geliştirilmiştir. Bunun için, Konya Organize Sanayi Bölgesinde faaliyet gösteren bir döküm fabrikasında çeşitli kalitelerde üretilen küresel grafitli dökme demir parçalarına ait 30 adet mikroskop görüntüsü kullanılmıştır. Temelde görüntü işleme metotlarından yararlanarak mikroskop görüntüleri segmente edilmiş, daha sonra mikro yapılardaki nodüllerin yeri, sayısı ve şekillerinin küreselliği hesaplanmıştır. Bu sayede küresel grafitli dökme demir parçalarının bilgisayar ortamında incelenmesi mümkün olmuş ve kalitelerinin otomatik olarak belirlenmesi adına bir ön çalışma ortaya konmuştur. Gerçekleştirilen simülasyonlar, görüntü işleme metotları ile mikroyapıların küresellik değerinin nicel olarak ortaya konabileceğini ve $\% 95,45$ 'lik doğruluk oranı ile nodül sayısının belirlenebileceğini göstermektedir.

\section{Determining the Nodularity and Sphericity of Ductile Cast Iron by Using Image Processing Methods}

\begin{abstract}
Foundries are one of the most important segments of the society, since they provide the production of important components in industry. In foundries, the molten materials obtained by melting different elements and combining them in some certain proportions, are subject to various procedures, and are given the desired shape by molding. The produced castings are used in many different areas such as automotive and weapon sector, aviation and maritime industry, and so on. Meanwhile, manually realizing the quality and
\end{abstract}

\footnotetext{
* Sorumlu Yazar: Konya Teknik Üniversitesi, Mühendislik ve Doğa Bilimleri Fakültesi, Elektrik-Elektronik Mühendisliği Bölümü, Konya, Türkiye, ORCID: 0000-0003-2277-9169, f171202059@ktun.edu.tr
} 
standardization procedures of the manufactured cast irons that have different properties based on the user requirements, by the engineers in industry causes serious loss of labor, time and cost.

Nowadays, the fast-growing technology diversifies the needs of users day by day. At this point, accelerating the quality process not only expedites all the following processes but also minimizes the loss of labor, time and cost. Considering this, a computer-aided system based on the nodularity and sphericity values of ductile cast iron is developed in this study. Therefore, 30 microscopic images of varying quality ductile cast iron samples, which were produced in a Casting Factory being operated in Konya Organized Industrial Zone, is utilized. Specifically, the microscopic images are segmented by using image processing methods, and then the location and number of the nodules in micro-structures and sphericity of their shapes are calculated. Hence, it has been possible to analyze the ductile cast iron samples in computer environment, and a preliminary study has been presented to detect their qualities automatically. The realized simulations show that sphericity value of the micro-structures can be presented quantitatively with image processing techniques, and number of the nodules can be detected with the accuracy rate of $95,45 \%$.

Keywords: Image Processing, Quality, Ductile Cast Iron, Sphericity, Nodularity, Segmentation.

\section{Giriş}

Doğadaki yenilenemez ham madde kaynaklarının, tüketim hızındaki eksponansiyel artış nedeniyle gitgide azalması, mevcut ham maddelerin doğru ve verimli bir şekilde kullanılmasını gerekli kılmaktadır. Bunun için ham maddelerin ve bunlardan elde edilen ürünlerin yapısına ve kalitesine göre sınıflandırılması ve optimum fayda sağlanacak biçimde kullanılması gerekmektedir. Bu sınıflandırma günümüzde hala birçok üretim tesisinde insanlar tarafindan manuel olarak yapılmaktadır. Ancak insan gözünün duyarlılığı, yorulma payı gibi faktörler sınıflandırmanın tam verimle ve hatasız bir biçimde gerçekleşmesini engellemektedir.

Öte yandan, olası hataların minimum seviyeye indirilmesi oldukça önemlidir. Aksi takdirde ham madde israfi, tüm proseslerin yeni baştan tekrarı gibi maddi ve manevi kayıplar kaçınılmaz olacaktır [1]. Bu bağlamda, insan gücü yerine görüntü işleme uygulamaları kullanılarak manuel sistemlerdeki hataların oldukça azaltılması ve işlem süresinin kısaltılması mümkündür. Oldukça esnek ve geniş bir kullanım alanına sahip olan bu uygulamalar günümüzde faaliyet gösteren hemen hemen bütün sektörlere uyarlanabilmektedir.

Döküm sektörüne bakıldığında en yüksek tonaja sahip ürünün dökme demirler olduğu görülmektedir. Döküm endüstrisinde bu denli büyük bir satış payına sahip olmalarının başlıca sebepleri, iyi bir mühendislik malzemesi olmaları ve düşük maliyetle üretilebilmeleridir. Uygun alaşımlandırma ve 1sıl işlemlerle dökme demirin özelliklerini çok geniş bir aralıkta değiştirmek mümkündür. Çeliklerle karşılaştırıldığında \%20-\%40 oranında daha ucuza mal edilebilmelerinin yanında daha iyi titreşim sönümleme ve katılaşma sırasında daha az hacim daralmasına uğrama gibi bazı önemli avantajlara da sahiptirler [2].

Başlıca dökme demir türleri beyaz, gri, temper ve küresel grafitli dökme demir olmak üzere dört ana sınıfta incelenebilir. Bu türler; dökülebilirlik, işlenebilirlik, güvenilirlik, titreşim söndürme kabiliyeti, aşınma ve korozyon direnci, üretim maliyeti gibi birçok açıdan farklılıklar göstermektedir. Dökme demirlerin mekanik özelliklerini etkileyen faktörler sertlik, çekme, charpy darbe ve yorulma deneyleri yapılarak ölçülmektedir [3] ve bu faktörler döküm profili boyutuna, mikroyapıya ve alaşım elementlerinin oranına göre değişmektedir.

Nodüler, sfero ve düktil demir gibi isimlerle de anılan küresel grafitli dökme demirlerde mikroyapı küreselliğinin yanı sıra grafit sayısının da çekme mukavemeti, süneklik ve işlenebilirlik gibi mekanik özellikleri etkilediği bilinmektedir [3]. Küresel grafit/nodül sayısı arttıkça daha düzgün ve homojen bir mikroyapı oluşmakta; bu durum karbür, perlit veya yapısı bozulmuş grafitlere sebep olabilecek elementlerin segregasyonunu azaltmaktadır [3]. Bunun yanında, nodül sayısı arttıkça grafitlerin boyutu küçülmekte ve çekme, yorulma ve kırılma özellikleri gelişmektedir. Küresel grafit sayısını arttırmak için kullanılan aşılama yönteminin grafitlerin küreselliğini de artırdığı, yani küresel grafit sayısını arttırmanın küreselliği geliştirmekle bağlantılı olduğu bilinmektedir [4]. Normal şartlarda grafit sayısının fazla olması yüksek kaliteye işaret etse de farklı boyutlarda parçalar için optimum grafit sayısı aralıkları belirlenmekte ve bu aralıktan çıkılması mekanik özellikleri olumsuz etkileyebilmekte, kaliteyi düşürebilmektedir [4]. Ayrıca küresel grafit sayısındaki artış mikroyapıdaki ferrit/perlit oranını etkilemekte, sayı arttıkça perlit oranı azalmakta, bu azalmanın etkisiyle mukavemet düşerken sünekliğin arttığı gözlenmektedir [5,6]. Dökümhanelerde küreselliği artırmak için uygulanan aşılama işleminden sonra, ferrit/perlit oranını belirlemek için dağlama işlemi de gerçekleştirilmektedir. Ancak dağlama işlemi nodüllerin gözle görülmesini zorlaştırdığından nodüllerin şekil ve sayısıyla ilgili manuel değerlendirme yapılmasını da zorlaştırmaktadır (Şekil-1).

Bu çalışmada, tüm bu hususlar göz önünde bulundurularak, küresel grafitli dökme demirlerin içerdiği nodüllerin yer ve sayısı ile küreselliğinin otomatik olarak belirlenmesine odaklanılmıştır. Morfolojik görüntü işleme metotları ile bilgisayar destekli bir sistem geliştirilmiş ve oldukça başarılı sonuçlar elde edilmiştir.

\section{Materyal ve Metot}

Bu çalışmada mikroskoptan elde edilen on beşi aşılama sonrası, on beşi dağlama sonrası olmak üzere toplamda otuz farklı küresel grafitli dökme demir parçasına ait mikroyapı görüntüsü kullanılmıştır. Bunlardan sekiz tanesi Şekil-2'de örnek olarak verilmiştir. 


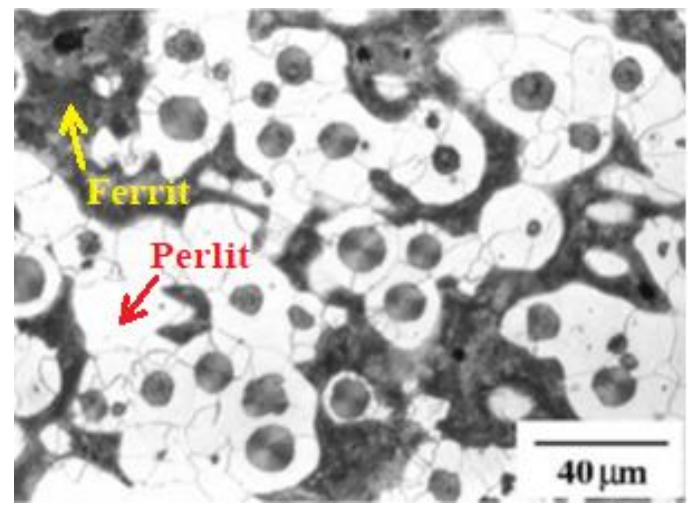

Şekil 1. Küresel grafitli dökme demir (dağlanmış).

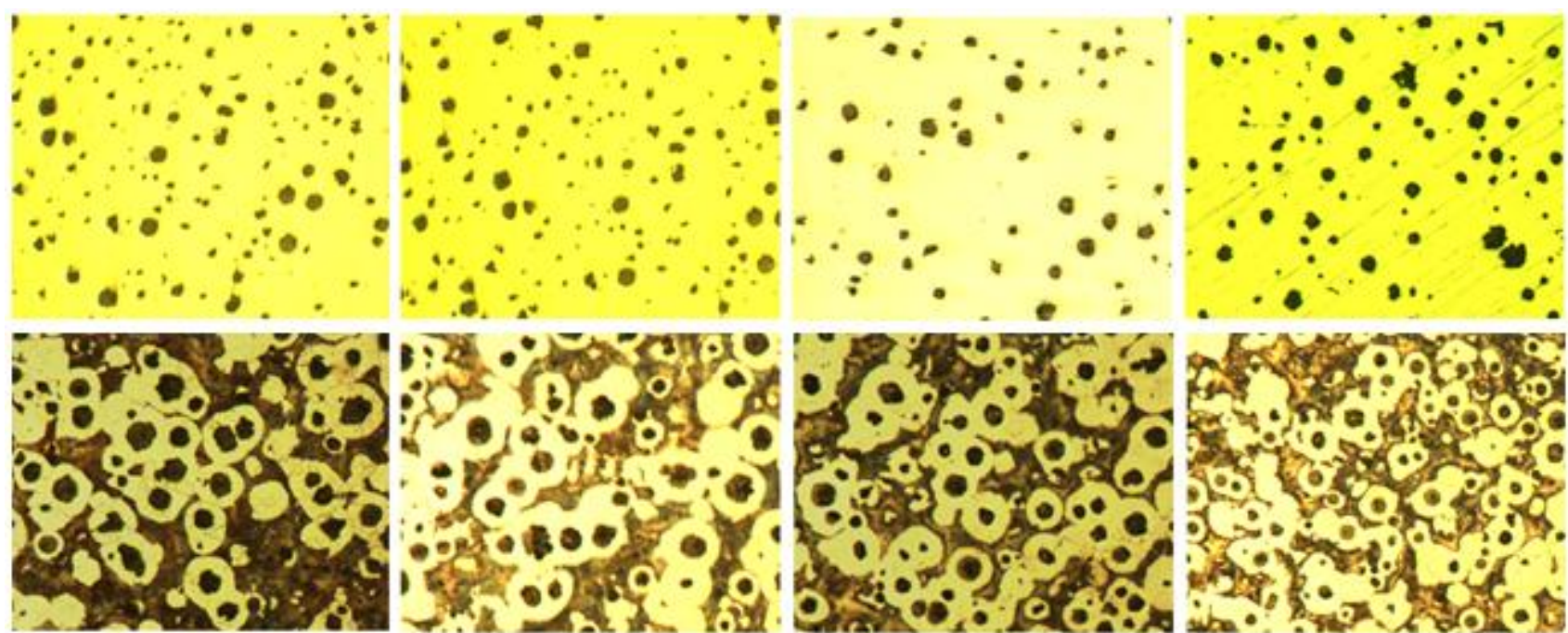

Şekil 2. Çalışmada kullanılan küresel grafitli dökme demir örneklerine ait mikroyapı görüntülerinden bazıları (ilk satır: aşılama sonrasında elde edilmiş görüntü örnekleri, ikinci satır: dă̆lama sonrasında elde edilmiş görüntü örnekleri).

Küresel grafitlerin yerini belirlemek dağlama işlemi sonrasında zorlaştığından, manuel sistemlerde sayım işlemi genellikle aşılanmış malzeme üzerinden dağlama işlemi öncesinde yapılmaktadır. Bu çalışmada ise görüntü işleme yöntemleri kullanılarak oluşturulan sistem sayesinde dağlama sonrası görüntüler üzerinden de nodül sayımı yapılabilmektedir.

Bilgisayar destekli olarak geliştirilen otomatik sistemde nodül yeri ve sayısı ile küresellik oranını bulmak için gerçekleştirilen işlemler, bu bölümde alt başlıklar halinde sırayla sunulmuştur.

\subsection{Nodül Yeri ve Sayısının Tespiti}

Küresel grafitli dökme demirlere ait mikroskoptan alınan mikroyapı görüntüleri kullanılarak nodül yeri ve sayısının belirlenmesi için uygulanan işlemler Şekil.3' te verilmiştir. Buna göre sırasıyla;

1. Renkli mikroyapı görüntüleri önce gri-ölçekli görüntüye, daha sonra ikili (binary) görüntüye dönüştürülmüştür. Böylece yalnızca 0 ve 1 değerlerinden oluşan bir görüntü matrisi elde edilmiştir.

2. İkili görüntüden belli bir piksel değerinin altında büyüklüğe sahip olan nesneler çıkarılmıştır. Böylece görüntü; toz, kir, iz, çizik gibi işe yaramayan kısımlardan temizlenerek gürültü giderme işlemi uygulanmış; ferritik ve perlitik bölgelerin netleştirilmesi ve nodüllerin daha belirgin hale getirilmesi sağlanmıştır.

3. Görüntü arka planında dağlama işlemi sonrasında oluşan ve nodül sayısını belirlemeyi zorlaştıran ferritik kısımlar yok edilerek yalnızca nodülleri içeren segmente edilmiş yeni bir görüntü elde edilmiştir.

4. Segmente edilmiş görüntü üzerindeki nodüller program yardımıyla sayılmış, toplam nodül sayısının yanında nodüllerin yerleri de renklendirilerek belirlenmiş ve kullanıcıya aktarılmıştır. 


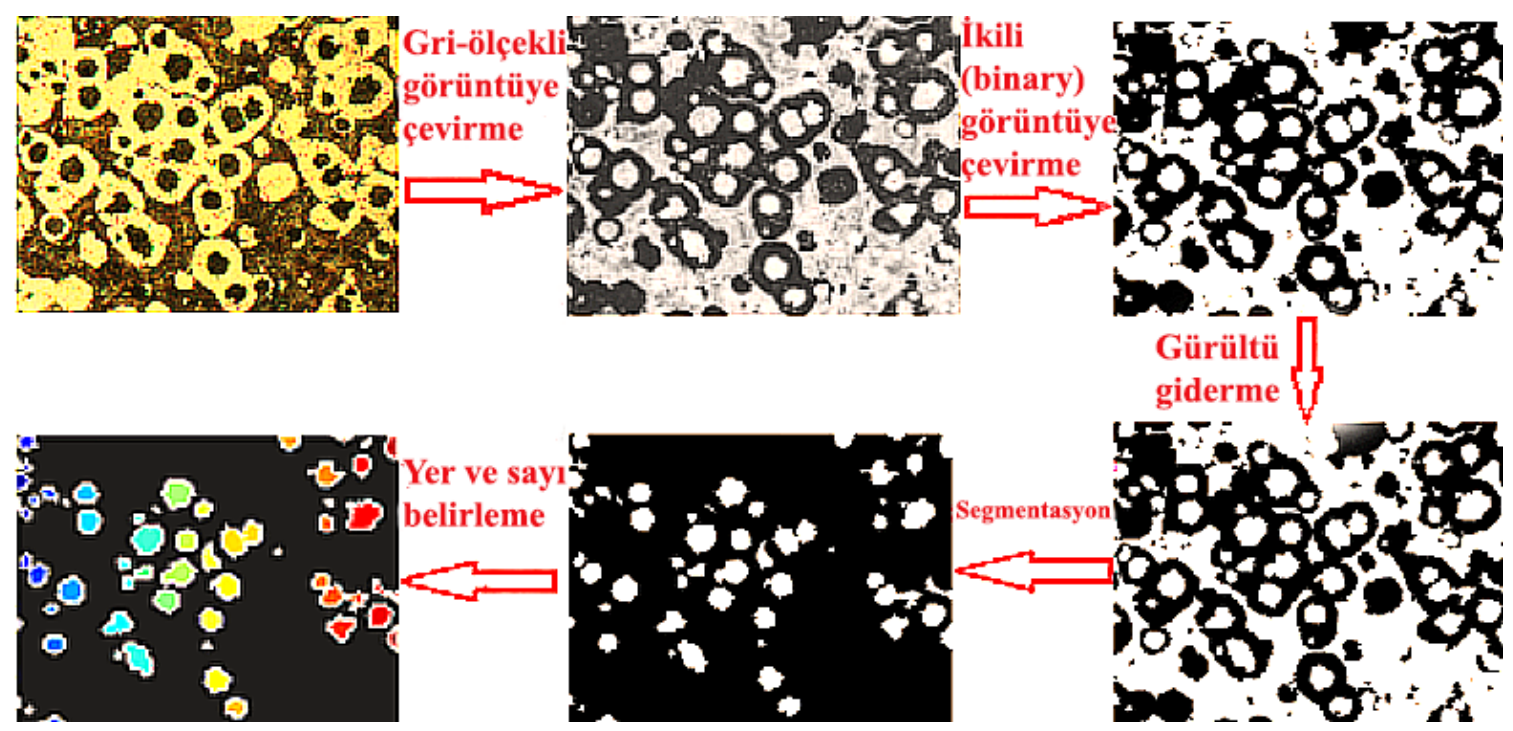

Şekil 3. Nodül yer ve sayısının belirlenmesi için uygulanan işlemler.

\subsection{Küreselliğin Belirlenmesi}

Mikroyapı görüntüleri kullanılarak yürütülen kalite proseslerinde mekanik özelliklerin belirlenmesi için gerekli olan bir diğer parametre ise küresel grafitli dökme demirin içerdiği nodüllerin küresellik oranıdır. Örneğin küresellik oranı \%30 azaldığında, akma mukavemeti \%10, çekme mukavemeti ise \%15 oranında azalmaktadır. Yüksek küresellik oranı, yorulma özelliklerini de iyileştirmektedir [4,7].

$\mathrm{Bu}$ sebeple, gerçekleştirilen çalışmanın önemli bir aşaması da küreselliğin belirlenmesidir. Her ne kadar küre şekil olarak üç boyut gerektirse de, grafitlerin küreselliği ile kastedilen, metalografik bir yüzeyde görülen kürelerin iki boyutlu kesitleridir [8]. Dolayısıyla görüntü üzerindeki grafitlerin daireye benzerlikleri hesaplanmaktadır.

Nodüllerin yeri ve sayısı tespit edildikten sonra küreselliğinin belirlenmesi için öncelikle her bir nodülün çevresi (l) ve alanı (S) hesaplanır. Küresellik oranı, nodüllerin çevre ve alan değerleri kullanılarak şu denklem ile bulunur:

$$
\kappa=4^{*} \pi^{*} S / l^{2}
$$

Burada $\kappa$ değeri 1'e yaklaştıkça küresellik oranı artarken, 0’a yaklaştıkça azalmaktadır.

Her bir nodüle ait küresellik değeri, görüntü üzerinde nodüllerin sol alt köşesinde kullanıcıya arayüz üzerinden sunulmaktadır. Bunun yanında tüm görüntüye ait ortalama küresellik değeri de hesaplanmaktadır. Nodüllerin küresellik oranları belirlendikten sonra elde edilen örnek bir görüntü Şekil 4' te verilmiştir.

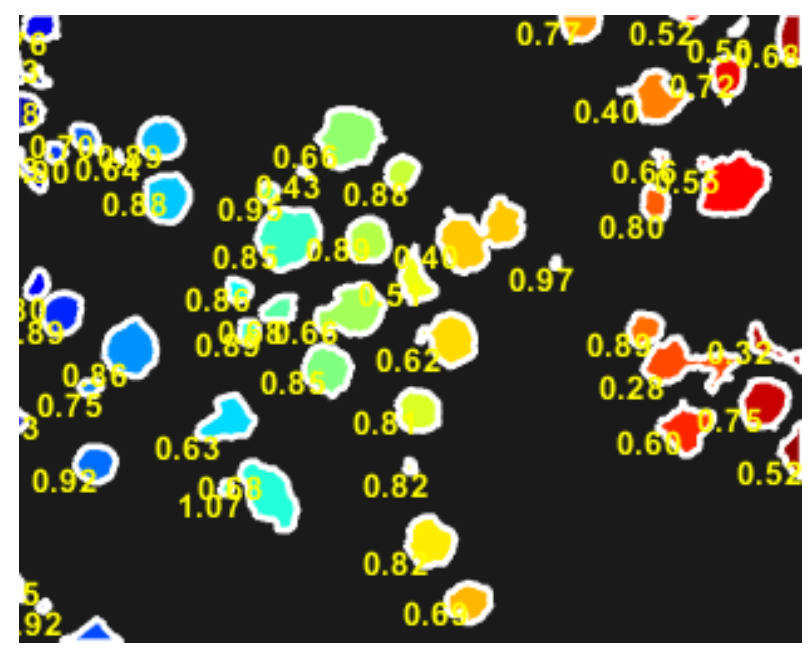

Şekil 4. Küresellik oranları belirlendikten sonra kullanıcıya aktarılan örnek bir mikroyapı görüntüsü. 


\section{Araştırma Sonuçları ve Tartışma}

Gerçekleştirilen çalışmalarda on beş adet dağlama işlemi sonrası ve on beş adet aşılama işlemi sonrası olmak üzere küresel grafitli dökme demirlere ait iki farklı türde görüntü kümesi incelenmiştir. Tasarlanan arayüz üzerinden önce aşılama sonrası, ardından da dağlama sonrası görüntüler seçilerek nodülarite hesaplanmıştır. Doğruluk oranının hesaplanabilmesi için, görüntüler üzerindeki nodüller manuel olarak da sayılmıştır. Görüntü işleme programıyla bulunan nodül sayısı manuel sayımla elde edilen gerçek nodül sayısına bölünerek doğruluk oranı hesaplanmış̧ır. Aşılama sonrası görüntülerin doğruluk oranı \%95,37 olarak belirlenirken, dağlama işlemi sonrası görüntüler için bu oran \%95,54 olarak bulunmuş̧ur. Nodül sayılarının belirlenmesi işleminde iki farklı küme için toplamda ortalama doğruluk değeri ise $\% 95,45$ ' tir.

Bilgisayar tarafından görüntü işleme metotları ile gerçekleştirilen nodül yeri ve sayısını belirleme işlem süresi (kullanılan işlemciye göre değiş̧ebilse de) ortalama olarak 0.45 saniye iken manuel sayım süresinin tam doğruluk için ortalama 300-350 saniye olduğu gözlenmiştir. Küreselliğin ise manuel olarak nicel bir şekilde belirlenmesi mümkün değilken, gerçekleştirilen yazılım sayesinde 0,65 saniyede işlem tamamlanabilmektedir.

Bu çalışma, küresel grafitli dökme demirlerin nodül sayısı ve küreselliğinin hesaplanmasında bilgisayar destekli bir sistemin kullanılması ve görüntü işleme tabanlı yöntemlerden yararlanılması yönüyle özgün değer taşımaktadır. Literatürde bu tarz başka bir çalışmaya rastlanmamıştır.

Elde edilen bulgular, doğruluk payı göz önüne alındığında görüntü işleme yöntemleri ile gerçekleștirilen inceleme ve nodül sayımının oldukça başarılı olduğunu ortaya koymuştur. İşlem süresi göz önüne alındığında ise nodülarite tespitinde manuel sistemlerin yerine bilgisayar destekli sistemlerin kullanılması ile çok ciddi bir zaman tasaffuru sağlanacağı açıktır.

Dağlama işlemi sonrasında mikroyapının ferrit/perlit oranının belirlenmesi de kalite proseslerinde sıklıkla kullanıldığından, bir sonraki aşamada bu oranın tespitini de içeren daha kapsamlı çalışmaların yapılması planlanmaktadır. Ayrıca yapay zeka yöntemleri ile dökme demirlerin mikroyapı görüntüleri kullanılarak tamamen otomatik bir şekilde kalitelerine göre sınıflandırılması da düşünülmektedir. Benzer şekilde diğer dökme demir türleri için de kalite süreçlerinin hızlandırılması mümkündür.

\section{Sonuç}

Bu bildiride, küresel grafitli dökme demirlerin bilgisayar destekli bir sistemle kalitesinin belirlenmesine yönelik bir ön çalışma gerçekleştirilmiştir. Bunun için Konya Organize Sanayi bölgesinde faaliyet göstermekte olan bir demir döküm fabrikasından elde edilen küresel grafitli dökme demirlere ait otuz adet görüntünün mikroyapıları incelenmiş ve görüntü işleme metotları ile $\% 95,45$ doğrulukla nodülarite hesaplanmıştır.

Ayrıca bu çalışma ile, döküm fabrikalarında mikroskop görüntülerinden tamamen tecrübeye dayalı varsayımlarla tahmini olarak belirlenen küresellik oranının, mikroyapı görüntüleri üzerinden bilgisayar ortamında nicel olarak hesaplanması sağlanmıştır.

\section{Teşekkür}

Yazarlar, bu çalışmada kullanılan mikroyapı görüntülerinin teminini sağlayan Canbilenler Döküm Mak. San. Tic. Ltd. Şti.' ye ve konu ile ilgili bilgi ve tecrübelerini paylaşan Metalurji ve Malzeme Mühendisi Ali Rıza Canbilen’e teşekkür eder.

\section{Kaynakça}

[1] Kopardaker P., Mital A. ve Anand S., (1993). Integrated Manufacturing Systems, vol.4, no. 1, 18-29.

[2] Bubenko, L., Konecna, R. ve Nicoletto, G., (2009). Observation of fatigue crack paths in nodular ast iron and ADI microstructures, Materials Engineering, 16, 13-18, Slovakia.

[3] Demirlek M., (2013). Küresel Grafitli Dökme Demirlerin Yüksek Çevrimli Yorulma Davranışına Silisyum Oranının Etkisi, Yüksek Lisans Tezi, İstanbul Teknik Üniversitesi Fen Bilimleri Enstitüsü, İstanbul.

[4] Swain, S. K., (2008). Effect of Chemistry and Processing Variables on the Mechanical Properties of Thin-wall Ductile iron castings, Yüksek Lisans Tezi, National Technology of University, Rourkela.

[5] Khalil-Allafi, J. ve Amin-Ahmadi, B., (2011). İnfluence of mold preheating and silicon content on microstructure and casting properties of ductile iron in permenant mold, Journal of iron and steel research, İnternational, 18,34-39, Tahran,

[6] Shinde, V. D., Ravi, B. ve Narasimbhan, K., (2012). Solidification Bhaviour and mechanical Properties of ductile Iron castings and varying thickness, International Journal of Cast Metals Research, 25, 364-373, India.

[7] Olsson, A., (2011.). Fatigue strength of truck components in cast iron, Yüksek Lisans Tezi, Chalmers University of Technology, Göteborg.

[8] Çetin A., (2016). El Kitabı 02: Küresel Grafitli Dökme Demir, Türkiye. 